\title{
Chewing Gum Dosage Form
}

National Cancer Institute

\section{Source}

National Cancer Institute. Chewing Gum Dosage Form. NCI Thesaurus. Code C42894.

A semi-solid composed of synthetic, polymerized polysaccharide and flavorings, intended to be chewed to release active and/or inert ingredient(s). 